\title{
Faktor yang Mempengaruhi Produksi Buah Naga Desa Nunmafo Kabupaten Timor Tengah Utara (Study Kasus Kelompok Tani Oefeu)
}

Mauritius Leu Naihelia,

${ }^{a}$ Fakultas Pertanian, Universitas Timor, Kefamenanu, TTU - NTT, Indonesia.Email: naihelimauritus57@gmail.com

\section{Article Info}

\section{Article history:}

Received 18 Desember 2019

Received in revised form 20 Desember 2019 Accepted 5 Januari 2020

$\mathrm{DO}$

https://doi.org/10.32938/ag.v5i1.861

Keywords:

Usahatani Buah Naga

Faktor Produksi

Cobb-douglass

\section{Pendahuluan}

Tanaman buah naga (Hylocereus costaricensis) memang belum lama dikenal, dibudidayakan, dan diusahakan di Indonesia. Tanaman dengan buah berwarna merah dan bersisik hijau ini merupakan pendatang baru bagi dunia pertanian di Indonesia. Budidaya tanaman buah naga merupakan salah satu peluang usaha yang menjanjikan karena pengembangannya sangat bagus di daerah tropis seperti di Indonesia (Putra, 2011). Buah naga merupakan salah satu komoditi hortikultura yang mempunyai potensi pasar cukup cerah.

Pengembangan buah naga di Indonesia mulai dilakukan di beberapa daerah. Jenis buah naga ada empat macam meliputi buah naga daging putih (Hylocereus undatus), buah naga daging merah (Hylocereus polyrhizus), buah naga daging super merah (Hylocereus costaricensis) dan buah naga kulit kuning daging putih (Selenicerius megalanthus). Iklim dan keadaan tekstur tanah di Indonesia mendukung untuk pengembangan buah naga. Komoditas buah naga mempunyai prospek yang cerah untuk peluang komoditas ekspor dan pasarnya masih terbuka lebar serta memiliki potensi yang sangat baik dikembangkan di Indonesia.

Efendi et al (2015) dalam penelitiannya dengan judul Faktor-Faktor Yang Mempengaruhi Produktifitas Usahatani Buah Naga (Studi Kasus di Desa Kemuning Lor Kecamatan Patrang Kabupaten Jember) berdasarkan analisisnya menyimpulkan bahwa Metode Analisis yang digunakan adalah metode analisi regresi linier berganda. Selama kurun waktu penelitian, sektor pertanian dapat menyerap banyak tenaga kerja. Koefisien Trend nilai produksi terkecil pada usaha tani buah naga adalah 19.229 sedangkan produksi terbesar adalah 30.640 $\mathrm{kg} /$ panen. Kontribusi sektor pertanian terhadap PDRB Kabupaten jember masih sangat kecil yakni rata-rata 0,011 persen per tahun.

Bowo (2010) dalam penelitiannya dengan judul faktor-faktor yan mempengaruhi produksi belimbing di Desa Betokan Kabupaten Demak. Variabel yang digunakan dalam penelitian ini adalah luas lahan; jumlah pohon; Jumlah pupuk; pemakaian pestisida dan pemakaian tenaga kerja. Data yang digunakan dalam penelitian ini menggunakan data primer dan data sekunder. Metode pengumpulan data menggunakan metode wawancara dan dokumentasi Pengolahan data dilakukan dengan menggunakan bantuan program Eviews vers 6. Metode yang digunakan adalah metode kuadrat terkecil (Ordinary Least Squares/ OLS) merupakan model regresi yang menghasilkan estimator linie tidak biasa yang terbaik (Best Linear Unbias Estimator/BLUE).

Kelompok Tani Oefeu merupakan salah satu Kelompok Tani di desa Nunmafo yang membudidayakan tanaman buah naga daging merah (Hylocereus polyrhizus) sejak tahun 2013. Berdasarkan data yang diperoleh dari 3 tahun terakhir yaitu tahun 2015 produksi buah naga sebanyak 48.960 buah/pohon, tahun 2016 produksi buah naga sebanyak 55.080 buah/pohon dan tahun 2017 produks buah naga sebanyak 61.200 buah/pohon.(Sumber: Kelompok Tani Oefeu tahun 2015-2017). Penelitian ini bertujuan untuk mengetahui gambaran umum usahatani dan faktor produksi yang mempengaruhi produksi buah naga di Kelompok Tani Oefeu Desa Nunmafo Kabupaten Timor Tengah Utara.

\section{Metode}

\subsection{Metode Pengambilan Sampel}

Metode yang digunakan dalam pengambilan sampel adalah purposive karena Desa Nunmafo merupakan salah satu penghasil buah naga di Kabupaten Timor Tengah Utara. Penelitian ini dilaksanakan pada bulan Januari 2019 sampa Mei 2019. Metode pengambilan data yang digunakan dalam penelitian ini adalah metode survei, wawancara, observasi, dan menggunakan data primer dan data sekunder. Sampel dalam penelitian ini adalah semua anggota Kelompok Tani Oefeu yang berjumlah 36 orang.

\subsection{Metode Analisis Data}

Gambaran usahatani buah naga di Desa Nunmafo dianalisis menggunakan metode deskriptif kualitatif dan untuk menganalisis fakto produksi yang mempengaruhi usahatani buah naga dianalisis menggunakan regresi berganda dalam bentuk fungsi bentuk produksi Cobb-Douglas.
Soekartawi (2003) menjelaskan fungsi produksi Cobb-Douglas merupakan fungsi atau persamaan yang melibatkan dua atau lebih variabel, dimana variabel yang satu disebut dengan variabel dependen, yang dijelaskan (Y) dan yang lain disebut variabel independent, yang menjelaskan (X). Penyelesaian hubungan antara $\mathrm{Y}$ dan $\mathrm{X}$ adalah bisa dengan cara regresi dimana variasi dari $\mathrm{Y}$ akan dipengaruhi oleh variasi dari $\mathrm{X}$. Dengan demikian kaidah pada garis regresi juga berlaku dalam penyesaian fungsi Cobb-Douglas.

Secara matematik, fungsi Cobb-Douglas tersebut dinyatakan oleh hubungan Y dan X maka :

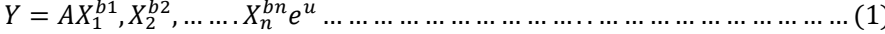
Bila fungsi Cobb-Douglas tersebut dinyatakan oleh hubungan $\mathrm{Y}$ dan $\mathrm{X}$ maka diubah menjadi bentuk linier berganda dengan cara melogaritmakan persamaan tersebut:

$L_{n} Y=A+b_{1} L_{n} X_{1}+b_{2} L_{n} X_{2}+b_{3} L_{n} X_{3}+b_{4} L_{n} X_{4}+b_{5} L_{n} X_{5}+e \ldots \ldots \ldots \ldots$

Dimana :

$\mathrm{Y}=$ Produksi buah naga $(\mathrm{Kg}$

$\mathrm{X}_{1} \quad=$ Luas lahan $(\mathrm{Ha})$

$\mathrm{X}_{2} \quad=$ Jumlah bibit $(\mathrm{Kg})$

$\mathrm{X}_{3} \quad=$ Pupuk $(\mathrm{Kg})$

$\mathrm{X}_{4} \quad=$ Tenaga Kerja $(\mathrm{HKO})$

$\mathrm{X}_{5} \quad=$ Pengalaman (tahun)

$\mathrm{A}=$ Intersep

e $\quad=$ Kesalahan penggangu (disturbance term)

$\mathrm{b}_{\mathrm{i}} \quad=$ Koefisien regresi faktor produksi ke-i $(\mathrm{i}=1,2,3,4,5)$,

Ln = Logaritma natural : 2,7182 (Gujarati,2003).

\section{Hasil dan Pembahasan}

\subsection{Gambaran Usahatani Buah Naga}

Gambaran usahatai buah naga yang dilakukan di lokasi penelitian meliputi persiapan lahan, penanaman, pemeliharaan, panen dan pasca panen.

\section{Persiapan Lahan}

Usahatani buah naga yang ada di lokasi penelitian di lakukan mulai dari persiapan lahan. Persiapan lahan di lakukan selama 1 bulan dengan jumlah 36 orang, persiapan lahan tersebut mencakup pemasangan tiang panjatan, prmbersihan lahan serta pengolahan lahan. Buah naga merupakan tanaman merambat sehingga dibutuhkan tiang panjatan untuk menopang pertumbuhan batang dan cabangnya. Bentuk model tiang panjatan dalam budidaya buah naga di Kelompok Tani Oefeu yaitu bentuk tunggal, dengan tinggi tiang 2,5 m. bagian atas tiang diberi ban bekas sepeda motor, dan besi dengan arah silang dengan ukuran $30 \mathrm{~cm}$. Anggota kelmpok tani Oefeu, melakukan pembersihan lahan dengan luas lahan 1 ha yang akan digunakan untuk budidaya tanaman buah naga dalam kurun waktu 14 hari. Lahan dibersihkan dengan cara membersihkan semak belukar, bebatuan yang berhamburan dan gulma yang ada didalam lahan budidaya tersebut, sehingga tidak dapat mengganggu tanaman utama (buah naga).

\section{Pengolahan lahan}

Lahan yang sudah dibersihkan setelah itu dibalik tanahnya dengan peralatan pertanian seadanya yaitu linggis. Dalam pengolahan lahan petan menggunakan cara penggolahan sistim jalur, bertujuan agar lapisan tanah bagian bawah tercampur dengan tanah lapisan bagian atas sehingga penyebaran humus atau bahan organik bisa merata keseluruh lapisan tanah. Selanjutnya pembuatan lubang tanam dengan kedalaman $25 \mathrm{~cm}$ dengan lebar lubang $60 \mathrm{~cm} \times 60 \mathrm{~cm}$ sesuai dengan model tiang panjatan yang digunakan. Lubang tanam yang sudah disiapkan lalu diisi dengan media berupa campuran pupuk organik, tanah, dan siram sampai basah. Dalam pengolahan lahan usahatani buah naga petan membutuhkan 16 hari untuk melakukan pengolahan lahan. 


\section{Penanaman}

Penanaman buah naga di lakukan semua anggota Kelompok Tani Oefeu (36 0rang) dengan jangka waktu selama 2 hari. Penanaman buah naga membutuhkan satu tiang panjat, tiang panjat berfungsi sebagai penopang tanaman karena tanaman buah naga merupakan tanaman merambat, sehingga tanaman buah naga membutuhkan panjatan. Penanaman buah naga pada satu tiang panjat ditanam empat bibit buah naga, keempat bibit ditanam mengelilingi tiang panjat. Setelah bibit ditanam timbun menggunakan tanah yang padat dan keempat bibit diikat menggunakan tali rafia sampai menyatu dengan tiang panjat agar tidak roboh.

\section{Pemeliharaan}

Pemeliharaan dilakukan secara teratur, pemeliharaan tanaman merupakan faktor penting yang mendukung keberhasilan budidaya buah naga. Upaya dalam pemeliharaan buah naga secara intensif meliputi penyiraman yang dilakukan pagi dan sore, pengikatan batang atau cabang bila sudah mulai tumbuh batang baru, pemupukan dengan menggunakan pupuk kandang (cirit sapi atau ayam) yang dilakukan dua kali dalam satu bulan, serta pengendalian hama penyakit tanaman menggunakan pestisida (sidametri) yang dilakukan satu kali dalam satu bulan. Dalam melakukan pemeliharaan semua anggota Kelompok Tani Oefeu yang berjumlah 36 orang bekerja sama.

\section{Panen}

Tanaman buah naga akan berbuah apabila tanaman buah naga sudah mencapai umur sekitar satu tahun sampai dua tahun. tanaman buah naga mampu berbuah sampai 15 tahun tergantung pemeliharaan. Musim panen buah naga biasanya berlangsung pada bulan September sampai Mei. Pemanenan buah naga dilakukan ketika buah naga sudah mencapai umur 50 hari terhitung sejak bunga sudah mulai mekar.

Kulit buah naga berwarna merah merata, pemanenan buah naga biasanya menggunakan pisau dan karung. Sebelum melakukan pemanenan perlu menyiapkan alat dan bahan seperti pisau yang akan digunakan untuk memotong tangkai buah naga dan karung untuk mengisi buah naga yang sudah di potong atau di pisahkan dari tangkainya. Kriteria buah naga yang siap dipanen antara lain:

- Buah berwarna merah.

- Struktur buah lembut atau tidak keras.

- Bunga pada bagian ujung buah naga telah mengering.

Cara memanen buah naga pilih buah yang telah memenuhi kriteria panen dan pegang bagian ujung buah naga, miringkan sedikit untuk memudahkan pemotongan buah naga, selanjutnya potong tangkai buah naga menggunakan pisau yang sudah di siapkan dan buah naga yang sudah di potong diisi dalam karung. Dalam pemanenan di Kelompok Tani Oefeu, semua anggota yang berjumlah 36 orang selalu bekerja sama dalam melakukan pemanenan dalam kurun waktu 1 hari.

\section{Pasca panen}

Setelah pemanenan dilakukan yaitu dilakukan pasca panen, dimana anggota Kelompok Tani Oefeu (36 orang) melakukan penyortiran yang memerlukan waktu dua atau tiga jam untuk memisahkan hasil panen buah naga yang cacat atau berukuran kecil, dari buah naga yang baik atau berukuran besar. Buah naga yang tidak termasuk dalam kriteria pemasaran, petani mengomsumsinya sedangkan buah naga yang baik dan berukuran besar siap dipasarkan.

\section{Faktor Yang Mempengaruhi Produksi Buah Naga Kelompok Tani \\ Oefeu}

Penelitian ini menggunakan 5 (lima) variabel bebas $(\mathrm{X})$ yakni $\left(\mathrm{X}_{1}\right)$ luas lahan, $\left(\mathrm{X}_{2}\right)$ jumlah bibit, $\left(\mathrm{X}_{3}\right)$ Pupuk, $\left(\mathrm{X}_{4}\right)$ jumlah tenaga kerja, $\left(\mathrm{X}_{5}\right)$ pengalaman, yang mempengaruhi $(\mathrm{Y})$ produksi buah naga Kelompok Tani Oefeu.

$$
\begin{gathered}
Y=9.568+1.066 X_{1}+0.729 X_{2}+0.105 X_{3}+1.271 X_{4} \\
+0.74 X_{5} \ldots \ldots \ldots \ldots(3)
\end{gathered}
$$

Tabel 1. Hasil Persamaan Faktor Produksi Buah Naga Kelompok Tani Oefeu

\begin{tabular}{llll}
\hline Variabel & Koefisien & t-Statistic & Prob. \\
\hline C & 9.568 & .693 & $.000^{\mathrm{a}}$ \\
X1(luas lahan) & 1.066 & .246 & $.000^{\mathrm{a}}$ \\
X2(jumlah bibit) & .729 & .211 & $.002^{\mathrm{b}}$ \\
X3(pupuk) & .105 & .066 & $.120^{\mathrm{c}}$ \\
X4(tenaga kerja) & 1.271 & .202 & $.000^{\mathrm{a}}$ \\
X5(pengalaman) & .74 & .131 & .578 \\
R-squared & 0,609 & & \\
Prob(F-statistic) & $0,000^{\mathrm{a}}$ & & \\
\hline
\end{tabular}

Keterangan : a,b, dan c signifikan pada $\alpha: 0,01,0,05$, dan 0,2

\section{Interpretasi Hasil Analisis Faktor Produksi Buah Naga Kelompok Tani Oefeu}

1. Pengaruh Luas Lahan Terhadap Produksi Buah Naga Kelompok Tani Oefeu Luas lahan mempengaruhi produksi buah naga di Kelompok Tani Oefeu dengan nilai 1,066. Ini berarti jika luas lahan meningkat $1 \%$ menyebabkan jumlah produksi jagung meningkat sebesar 1,066 persen. Hal ini sesuai dengan hasil penelitian sebelumnya bahwa luas lahan mempunyai pengaruh yang positif terhadap produksi (Sipayung, 2019)

2. Pengaruh Jumlah Bibit Terhadap Produksi Buah Naga Kelompok Tani Oefeu Jumlah bibit berpengaruh secara positif terhadap produksi buah naga dengan nilai 0,729 . Ini menunjukkan bahwa jika jumlah benih meningkat $1 \%$ menyebabkan jumlah produksi buah naga meningkat sebesar 0,729 persen. Ha ini tidak berbeda dengan hasil penelitian sebelumnya bahwa jumlah bibit mempengaruhi secara positif produksi (Falo et. al.,2016)

3. Pengaruh Pupuk Terhadap Produksi Buah Naga Kelompok Tani Oefeu Penggunaan pupuk berpengaruh secara positif dengan produksi buah naga Kelompok Tani Oefeu dengan nilai 0,105. Angka tersebuat memiliki arti jika tenaga kerja meningkat $1 \%$ maka terjadi peningkatan produksi sebesar $0,105 \%$. Hasil penelitian ini tidak berbeda jauh dengan Andayani (2018) pupuk berpengaruh positif terhadap produksi.

4. Pengaruh Penggunaan Tenaga Kerja Terhadap Produksi Buah Naga Kelompok Tani Oefeu.

Penggunaan tenaga kerja berpengaruh positif terhadap produksi buah naga dengan nilai 1.271. Hal ini menunjukkan jika pengalaman meningkat $1 \%$ maka produksi buah naga meningkat sebesar 1.271 persen. Hasil penelitian ini sesuai dengan Lamusa (2005) penggunaan tenaga kerja mempengaruhi secara positif terhadap produksi.

5. Pengaruh Pengalaman Terhadap Produksi Buah Naga Kelompok Tani Oefeu Lama pengalaman berusaha tani mempunyai pengaruh positif terhadap produksi buah naga dengan nilai 0,74 . Ini berarti jika lama pengalaman meningkat sebesar $1 \%$ maka produksi buah naga meningkat sebesar $0,74 \%$. Hasil penelitian ini berbeda dengan Ananda (2009) pengalaman memiliki pengaruh negatif terhadap produksi.

\section{Koefisien Determinasi}

Koefisien determinasi ialah variabel terikat $(\mathrm{Y})$ yang mampu dijelaskan oleh seluruh variabel bebas (X) dalam model nilai koefisien determinas merupakan perbandingan antara jumlah kuadrat regresi dengan kuadrat total. Dari Tabel 1. dikatakan bahwa faktor luas lahan, jumlah bibit, pupuk, penggunaan tenaga kerja dan pengalaman berusahatani memiliki pengaruh sebesar $60,9 \%$ terhadap produksi usahatani buah naga, sisanya sebesar $39,1 \%$ dipengaruhi oleh faktor lain yang tidak diteliti dalam penelitian ini.

\section{Uji Simultan atau Secara Serempak}

Uji $\mathrm{F}$ adalah untuk mengetahui apakah variabel bebas dalam model persamaan faktor produksi buah naga Kelompok Tani Oefeu memiliki pengaruh secara bersama-sama terhadap variabel terikat. Variabel bebas yaitu luas lahan, jumlah bibit, pupuk, penggunaan tenaga kerja, dan lama pengalaman berusahatani . Pada Tabel 1 dapat dilihat dari probabilitas $\mathrm{F}$ hitung 0,000 Variabel bebas berpengaruh nyata terhadap variabel terikat dengan $\alpha=1 \%$.

\section{Simpulan}

Berdasarkan hasil penelitian dapat di simpulkan bahwa :

1. Gambaran umum usahatani buah naga sebagai berikut : 1.Persiapan lahan; Persiapan lahan di lakukan selama 1 bulan. 2) Pengolahan lahan; Dalam pengolahan lahan petani menggunakan cara penggolahan sistim jalur. 3) Penanaman; Penanaman buah naga di lakukan semua anggota Kelompok Tan Oefeu (36 0rang) dengan jangka waktu selama 2 hari. 4).Pemeliharaan; pemeliharaan tanaman merupakan faktor penting yang mendukung keberhasilan budidaya buah naga. 5) Panen; Tanaman buah naga akan berbuah apabila tanaman buah naga sudah mencapai umur sekitar satu tahun sampai dua tahun. 6) Pasca panen; anggota Kelompok Tani Oefeu (36 orang) melakukan penyortiran.

2. Faktor yang mempengaruhi produksi buah naga secara signifikan adalah luas lahan, jumlah bibit, penggunaan pupuk dan penggunaan tenaga kerja. Semua faktor produksi memiliki pengaruh yang positif.

\section{Pustaka}

Ananda, C. F. (2009). Faktor-Faktor Yang Mempengaruhi Produksi Padi Studi Kasus di Kecamatan Nogosari, Boyolali, Jawa Tengah. WACANA, Jurnal Sosial dan Humaniora, 12(1), 179-191.

Andayani, S. A. (2018). Faktor-faktor yang mempengaruhi produksi cabai merah. Mimbar Agribisnis: Jurnal Pemikiran Masyarakat Ilmiah Berwawasan Agribisnis, 1(3), 261-268.

Bowo, 2010. Analisis faktor-faktor yang mempengaruhi produksi belimbing di Desa Betokan Kabupaten Demak.

Badan Pusat Statistik. 2018. Kecamatan Insana dalam angka. Badan Pusat Statistik.Kabupaten Timor Tengah Utara.

Efendi, S, M. Suswandi, E. Fivien, M. 2015. Faktor-Faktor Yang Mempengaruhi Produktifitas Usahatani Buah Naga (Studi Kasus di Desa Kemuning Lor Kecamatan Patrang Kabupaten Jember). Universitas Jember. Jember

Falo, M., Kune, S.J., Hutapea, A.N. \& Kapitan, O.B. 2016. Faktor-Faktor yang Mempengaruhi Produksi dan Strategi Pengembangan Usahatani Bawang Putih di Kecamatan Miomaffo Barat, Kabupaten Timor Tengah Utara. AGRIMOR, 1(04): 84-87.

Gujarati N. Damodar. 2003. Basic Econometric, Fourt Edition. New York: McGraw-Hill 
Lamusa, A. (2005). Faktor-Faktor Yang Mempengaruhi Produksi Kelapa Dalam

Di Desa Labuan Lele Kecamatan Tawaeli Kabupaten

Donggala. Agroland: Jurnal Ilmu-ilmu Pertanian, 12(3).

Nazir M. 1988. Metode Penelitian. Ghalia Indonesia. Jakarta.

Putra. 2011. Budidaya Buah Naga. Jakarta: Laksana.

Soekartawi. 2003. Teori Ekonomi Produksi dengan Pokok Bahasan Analisis Fungsi Cobb Douglas. CV Rajawali. Jakarta.

Sipayung, B. P., \& Ginting, R. (2019). Analisis Faktor Penawaran Kentang di Provinsi Sumatera Utara (Periode 2003-2012). Agrimor, 4(1), 7-8. 